\title{
Boardgame Penunjang Perkembangan Kosakata Bahasa Indonesia untuk Keluarga
}

\author{
Avis Triastara dan Nugrahadi Ramadhani \\ Departemen Desain Komunikasi Visual, Fakultas Arsitektur Desain dan Perencanaan, \\ Institiut Teknologi Sepuluh Nopember (ITS) \\ e-mail: avistriast@gmail.com
}

\begin{abstract}
Abstrak-Bahasa Indonesia merupakan alat komunikasi, baik melalui lisan mapun tulisan yang digunakan sebagai bahasa pengantar dalam pendidikan nasional. Namun berdasarkan Renstra Badan Bahasa kompetensi siswa dalam bidang Bahasa Indonesia rendah. Hal ini disebabkan motede pembelajaran oleh guru di sekolah kurang kreatif, Sehingga diperlukan sebuah media kreatif yang dapat menunjang pembelajaran Bahasa Indonesia khususnya pada pengembangan kosakata. Konsep desain media boardgame ini adalah Tangkas Bermain Kata, kata tangkas mewakili elemen kompetitif sekaligus menyampaikan pesan bernuansa cepat dan tepat, lalu bermain mewakili elemen permainan, kreatifitas dan aktifitas membaca, menulis dan mendengar yang dikemas dalam mekanik boardgame, sedangkan kata mewakili konten utama boardgame, sehingga diharapkan pemain tidak hanya cepat dalam menebak kata namun juga tepat sesuai dengan kaidah kebahasaan yang ada. Permainan ini dirancang melalui serangkaian metode penelitian diantaranya studi literature, In-Depht Interview, Prototyping dan Playtesting, sehingga menghasilkan sebuah boardgame kosakata Bahasa Indonesia yang tepat bagi usia 8 tahun keatas. Berdasarkan user test yang telah dilakukan boardgame tangkas berkata dapat mengakomodasi kegiatan pembelajaran kosakata Bahasa Indonesia yaitu mendengarkan, membaca, memirsa, berbicara dan menulis. Namun perlu pengembangan lebih lanjut untuk menentukan variable mekanik yang tepat agar pengalaman bermain dapat ditingkatkan.
\end{abstract}

Kata Kunci-Bahasa Indonesia, Keluarga, Perkembangan Kosakata, Permainan Papan.

\section{PENDAHULUAN}

$\mathrm{P}$ ERKEMBANGAN Industri Kreatif ranah permainan Interaktif saat ini mengalami perkembangan di Indonesia. Hal ini dibuktikan dengan terbentuknya Asosiasi Game Indonesia (AGI) dan Asosiasi Pegiat Industri Board Game Indonesia (APIBGI) pada tahun 2015 lalu. Diikuti dengan serangkaian acara bertajuk game yang diselenggarakan di berbagai kota. Perkembangan Industri Boardgame sendiri merupakan fenomena yang menarik. Dimana Industri ini tetap berkembang, di tengah gempuran konten - konten berbasis digital baik di Dunia maupun di Indonesia. Bahkan situs Crowdfunding Kickstarter.com menulis bahwa Boardgame mengasilkan pendanaan enam kali lebih besar dibanding videogame.

Sedangkan di Indonesi, terdapat Waroong wars salah satu boardgame lokal, mampu terjual 1942 buah hingga Mei 2016 dan menghasilkan omzet sekitar Rp 336.700.000, dengan $67 \%$ total penjualan melalui Gramedia. Sedangkan sisanya melalui Manikmaya, mandiri oleh desainer, dan kompasstore.

Melihat fenomena diatas peneliti merespon fenomena tersebut dengan melakukan penelitian untuk merancang sebuah game berplatform boardgame dengan tema lokal Indonesia. Dari berbagai konten lokal yang ada seperti budaya, sejarah dan bahasa. Tema Bahasa Indonesia menarik untuk diangkat dan dijadikan konten permainan baik itu boardgame maupun Cardgame.

Bahasa Indonesia sendiri di kehidupan masyarakat mengalami perkembangan pada dua dekade ini. Tahun 2010 prosentase penduduk yang menggunakan Bahasa Indonesia sebesar 19,94 persen [1]. Namun perkembangan ini tidak diimbangi dengan kemampuan masyarakat dalam berbahasa Indonesia. Tertuang dalam Rencana Strategi Badan Bahasa tahun 2015-2019 di bawah Kemendikbud, kondisi dan permasalahan saat ini ialah [2]:

1. Rendahnya kemahiran membaca (Reading Skill) dalam pengukuran PISA-OECD tahun 2012.

2. Rendahnya UN Bahasa Indonesia.

Ibu Lakhsmi melalui In-depth Interview yang penulis lakukan, memaparkan bahwa kondisi kebahasaan saat ini dikarenakan Guru-guru Bahasa Indonesia yang bisa mengajarkan pelajaran Bahasa Indonesia secara kreatif dan menyenangkan sangat jarang.

Menggunakan konten Bahasa Indonesia dalam mekanisme permainan boardgame tentu akan menciptakan situasi pembelajaran yang efektif dan menyenangkan, sehingga dapat menjadi salah satu nilai tambah yang dapat ditawarkan kepada target audiens.

\section{A. Identifikasi Masalah}

1. Tren perkembangan penggunaan Bahasa Indonesia tidak di imbangin dengan kemampuan Berbahasa Indonesia yang baik dan benar.

2. Sangat jarang Guru Bahasa Indonesia yang mengajarkan pelajaran Bahasa Indonesia secara kreatif dan menyenangkan

\section{B. Rumusan Masalah}

Bagaimana merancang sebuah boargame untuk keluarga dengan konten Kebahasaan Indonesia sebagai edukasi perkembangan kosakata Bahasa Indonesia untuk usia 8 tahun keatas?

\section{C.Batasan Masalah}

Batasan perancangan ini hanya mendesain media permainan berplatform boardgame dengan konten seputar Kebahasaan Indonesia yaitu Kosakata, Ejaan dan Diksi yang melalui serangkaian metode Studi Literatur, Depth Interview, Prototyping dan User Testing. Aspek Desain yang digunakan berupa desain layout dan penggayaan visual. 
- Wroory vars - Pagdariar raguakra *Pefunjen Joetbio

Gambar 1. Hasil penjualan Waroong Wars.

\section{D.Tujuan}

Menciptakan media alternatif yang mampu menarik minat dan meningkatkan khasanah kosakata Bahasa Indonesia serta materi-materi seputar kaidah Kebahasaan Indonesia di kalangan anak muda.

\section{STUDI ACUAN}

\section{A. Landasan Teori}

1. Bahasa Indonesia sebagai Konten Permainan

Bahasa Indonesia dalam pendidikan formal memiliki beberapa aspek kompetensi untuk dikembangkan, berdasarkan kurikulum 2013, kompetensi ketrampilan berbahasa ditekankan pada kemampuan mendengarkan, membaca, memirsa, berbicara dan menulis. Kurangnya pengalaman pembaca menyenimbulkan kesulitan memahami konteks sebuah bacaan, namun dengan memperbanyak khasanah kosakata dapat membantu pemahaman konteks bacaan dengan lebih mudah.

2. Desain Permainan

Desain permainan terdiri dari beberapa elemen permainan seperti mekanik permainan, yang terdiri dari goal dan peraturan permainan, kondisi menang, durasi bermain dan aksi giliran pada setiap pemain.

3. Gaya Visual dan Karakter

Gaya visual digunakan untuk mengasosiasikan bagaimana objek terlihat, setiap orang melihat dan menilai benda secara berbeda, terdapat beberapa aspek yang dapat digunakan untuk membedakan sebuah gaya visual yaitu berdasarkan subjeknya, teknik yang digunakan, properti visual dan torehan garis yang diberikan.

\section{Layout pada Kartu}

Dalam mendesain sebuah card game diperlukan kaidah layout untuk menentukan hierarki visual agar informasi pada kartu dapat terkomunikasikan dengan baik ke pemain. Beberapa yang perlu diperhatikan pada informasi adalah penggunaan simbol, kata yang efektif, tipografi sesuai konteks, backgorund dan Ilustrasi, harus sesuai dengan konteks informasi pada kartu.

\section{Target market Boardgame Keluarga}

Berdasarkan studi kasus Eurogamer [3], boardgame keluarga memiliki beberapa karakteristik sebagai berikut; dapat dimainkan antara 20-90 menit, persiapan waktu yang singkat, aturan permainan yang sederhana, mekanik yang bersifat kooperatif dan tidak konfrontasional dan Fase menunggu yang singkat.

\section{B. Studi Eksisting}

\section{Codename}

Boardgame Codename merupakan boardgame berbasis kata-kata dimana mekanik utama permainannya adalah membagi pemain menjadi dua tim lalu, setiap ketua tim memberi petunjuk pada setiap anggota timnya mengenai kata(codename) yang telah ditentukan oleh kartu.

\section{Chameleon}

Chameleon merupakan boardgame berbasis kata dengan genre social deduction, menggunakan berbagai mekanik seperti Bluffing dan Giving Clue. Konten Kata pada boardgame ini disajikan dengan cara pengelompokan kata berdasarkan kategori tertentu, seperti Tema "Drinks" berisi kelompok kata seperti "Ice Tea", "Juice", dan "Milk".

3. Taboo

Boardgame Taboo adalah "wordgame" dengan mekanik yang hampir sama dengan Codename, dimana pemain memberikan petunjuk mengenai sebuah kata, yang tidak boleh disebutkan kepada teman satu Tim dalam durasi waktu yang telah ditentukan.

\section{METODOLOGI PENELITIAN}

\section{A. Pra Riset}

Dalam pra riset dilakukan pengumpulan data perihal kondisi Kebahasaan di Indonesia dan tren boardgame, untuk melihat fenomena yang ada untuk dijadikan pertimbangan dalam mengambil tema judul.

\section{B. Riset Konten dan Target Audiens}

\section{Studi Literature}

Studi Literatur pada buku-buku Kebahasaan Indonesia seperti "Terampil Berbahasa Indonesia" karya Dewi Kusumaningsih Dan Kawan-kawan, Bahasia Indonesia 1 untuk kelas 1 SD dan MI karya Karsidi. Lalu Jurnal Ilmiah dan artikel mengenai perkembangan bahasa dan kosakata pada laman web seperti education.com, raisingchildren.net.au, dan Child-Encyclopedia.com.

\section{In-Depth Interview 1 dan 2}

Interview dengan praktisi di bidang Pendidikan dan Industri Kreatif untuk menggali permasalahan yang tidak terlihat di perspektif penulis. Praktisi yang akan direncanakan adalah Mayla Erna, $C E O$ Indonesia Writing Edu Center (IWEC) dan Laksmi Puspitowardhani, CEO Invention $\mathrm{CO}$.

\section{Riset Gameplay}

\section{Prototype}

Proses merancang prototype yang didasarkan pada hasi InDepth interview 1. Refinement terhadap prototype diprioritaskan berdasarkan affinity diagram dari hasil InDepth Interview 1 dan affinity diagram dari proses Playtesting. 


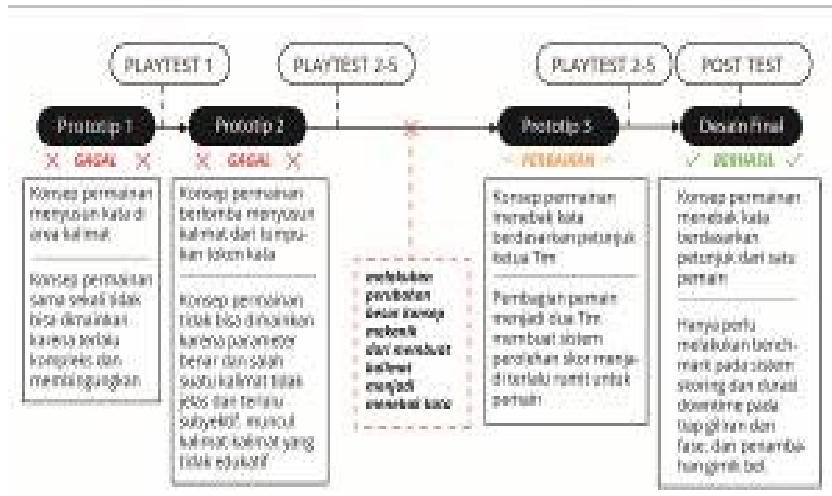

Gambar 2. Proses iterasi Prototyping Boardgame tangkas berkata.

\section{Playtesting}

Merupakan proses uji coba prototype terhadap target audience dengan jumlah minimum yang telah ditentukan. Proses playtesting untuk menguji keberhasilan mekanisme permainan, Content awarness, tingkat replayabilty produk, dan daya tarik permainan.

\section{Eksplorasi Konten}

Materi Konten kartu dibuat berdasarkan 10 tema yang disajikan pada Buku diktat Bahasa Indonesia 1 untuk kelas 1 SD dan MI. Hal ini guna mengakomodasi keseluruhan materi kosakata yang tersaji dalam buku diktat.

\section{KONSEP DESAIN}

\section{A. Konsep Dasar}

Gambaran umum konsep perancangan ini adalah merancang sebuah permainan boardgame yang memiliki value berupa konten edukasi berbahasa Indonesia untuk mengasah kemampuan pemain untuk mendeskripsikan konsep kosakata Bahasa Indonesia.

\section{B. Core Value}

Berdasarkan hasil riset terbentuklah keyword "TANGKAS" sebagai sub-tema, sehingga ketika tema utama dengan subtema digabung dapat menjadi sebuah konsep Boardgame yaitu TANGKAS BERMAIN KATA. TANGKAS mewakili elemen kompetitif sekaligus menyampaikan pesan bernuansa "cepat" dan "tepat", lalu BERMAIN mewakili elemen permainan, kreatifitas, dan aktivitas membaca, menulis dan mendengar yang terkemas dalam mekanik permainan. Sedangkan "KATA" mewakili konten utama permainan. Sehingga, diharapkan pemain tidak hanya cepat dalam menebak kata namun juga tepat sesuai kaidah kebahasaan yang ada.

Melalui konsep TANGKAS BERMAIN KATA, dihasilkan sebuah nama permainan yaitu "TANGKAS BERKATA". Konsep nama ini tidak hanya mengkomunikasikan mekanik permainan menebak kata namun juga memiliki arti berkomunikasi atau berbicara, dengan menempatkan istilah "Berkata" sebagai aktivitas utama dalam Boardgame dan "Kata" sebagai konten utama dalam permainan.

\section{Konsep Desain}

Setelah Core Value permainan TANGKAS BERKATA oleh peneliti rumuskan, langkah berikutnya adalah merumuskan keyword visual sebagai acuan referensi dan kriteria desain visual yang akan digunakan oleh peneliti untuk mendesain visual permainan untuk mengkomunikasikan core value permainan.

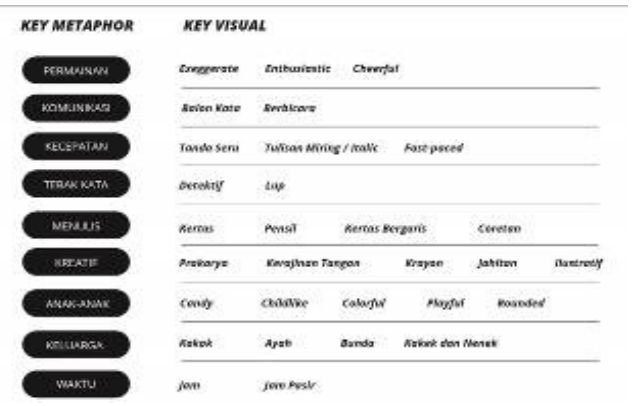

Gambar 3. Rumusan Key Methapor menjadi Key Visual Boardgame Tangkas Berkata.

\section{D.Kriteria Desain}

1. Karakter

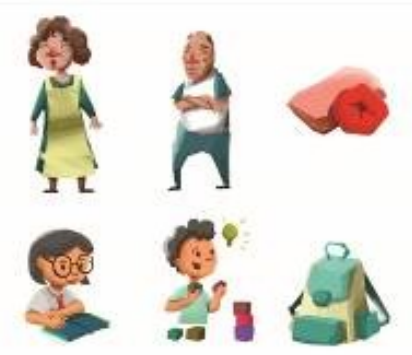

Gambar 4. Karakter dan gaya visual Boardgame Tangkas Berkata.

Secara estetik, masing-masing karakter akan memiliki beberapa warna ciri khas yang menggambarkan kepribadian dari karakter tersebut. Penggunaan warna dan tone warna yang vibran akan sering ditemui, hal ini agar ilustrasi cenderung menonjol dibanding dengan antar muka kartu yang berwarna pastel.

2. Warna

Penggunaan Palet warna didasarkan pada metafora keyword konsep BERMAIN dimana keyword ini diasosiasikan dengan permainan, kreatifitas, Anak-anak, yang begitu dekat dengan Pastel, Candy, Soft dan Colorful.
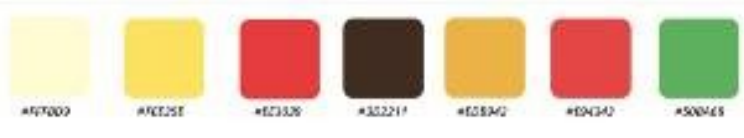

Gambar 5. Palet warna pada setiap elemen visual permainan.

3. Elemen Visual

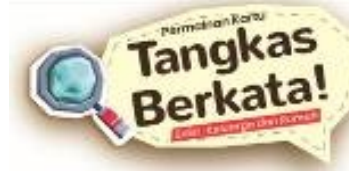

Gambar 6. Logo permainan berserta perlakuannya pada setiap bidang.

Tanda Seru ditambahkan pada akhir judul untuk menunjukkan kesan cheerful dan enthusiastic. Kemiringan pada logo menggambarkan kesan playful yang merupakan turunan dari keyword BERMAIN.

4. Mekanik Permainan

a. Premis Mekanik: 
TANGKAS BERKATA adalah sebuah permainan kartu menebak dan mencari kata berdasarkan petunjuk yang diberikan oleh ketua Tim. Anggota Tim menebak hanya mengandalkan daftar kata yang ada dan suara dari ketua Tim.

b. Goal permainan:

Meraih poin sebanyak-banyaknya! Siapa yang meraih poin terbanyak diakhir permainan, adalah pemenangnya!

5. Spesifikasi Ukuran dan Jumlah Elemen Permainan

Berikut adalah spesifikasi ukuran kartu dan beserta jumlahnya pada konsep dasar permainan Duel Bahasa. Ukuran pada kartu di sesuaikan dengan standar Trading Card Game Nasional. Dan jumlah masing-masing elemen permainan disesuaikan pada hasil playtesting dan eksperimental research.

Tabel 1.

Spesifikasi komponen permainan

\begin{tabular}{lll}
\hline \hline Komponen permainan & Dimensi & Jumlah \\
\hline Kartu Kosakata & $6,35 \mathrm{~cm} \mathrm{x} \mathrm{8,8} \mathrm{cm}$ & 320 \\
Packaging & $23,5 \mathrm{~cm} \mathrm{x} \mathrm{18,5} \mathrm{cm} \mathrm{x} \mathrm{4}$ & 3 \\
& $\mathrm{~cm}$ & \\
Papan Pencatat & $14,5 \mathrm{~cm} \mathrm{x} \mathrm{10cm}$ & 6 \\
Desain Papan Utama & $16,5 \mathrm{~cm} \mathrm{x} \mathrm{20,5} \mathrm{x} \mathrm{2}$ & 1 \\
Buku Aturan Permainan & $14 \mathrm{~cm} \mathrm{x} \mathrm{9,5} \mathrm{cm}$ & 1 \\
Spidol Board marker & - & 6 \\
Timer & - & 1 \\
\hline \hline
\end{tabular}

\section{V.PEMBAHASAN DESAIN}

\section{A. Hasil Akhir Desain Layout Kartu}

Penyederhanaan kartu pada desain akhir kartu dilakukan karena pada mekanik permainan, mengalami perubahan besar. Dibandingkan dengan rough design. Desain akhir menghilangkan elemen informasi berupa poin pada kartu dan flavor teks.
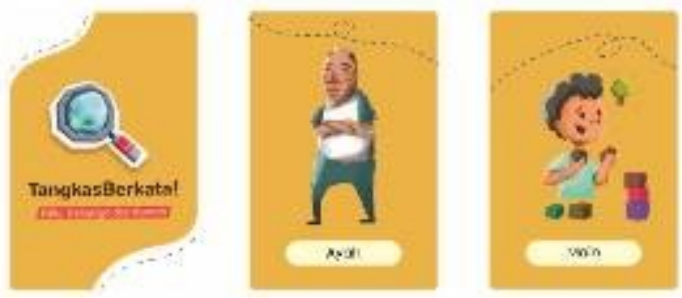

Gambar 7. Final Design Kartu dan antar muka.
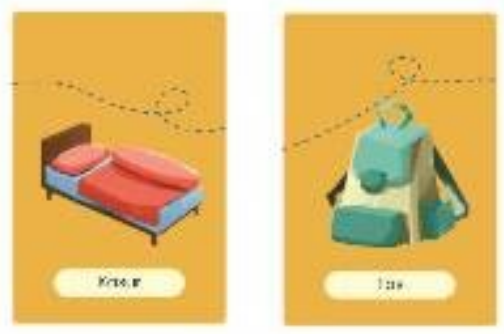

Gambar 8. Final Design Kartu dan antar muka.

Hal ini dikarenakan mekanik permainan berbasis kecepatan, sehingga desain yang tidak terlalu eklektik pada muka kartu diperlukan agar pemain dapat fokus memproses informasi pada ilustrasi dan teks yang tertera.

\section{B. Hasil Akhir Desain Papan Permainan}

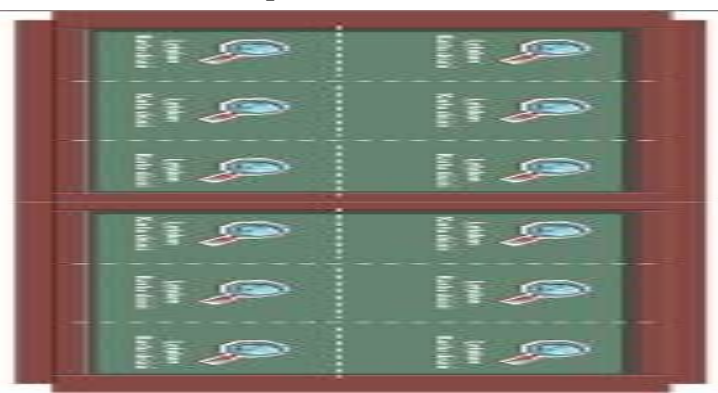

Gambar 9. Hasil akhir desain papan permainan

Desain akhir papan mengakomodasi kebutuhan mekanik permainan akhir yang hanya menggunakan elemen kartu kosakata dalam bermain. penggunaan papan kosakata diletakan pada posisi tegak. Dan menutupnya seperti sebuah buku. permainan mampu menampilkan 12 kartu sekaligus dapat berfungsi untuk memperlihatkan kartu hanya pada satu pemain. Fungsi desain papan permainan menunjang sepenuhnya pengalaman bermain yang cepat dan mudah.

\section{Hasil Akhir Desain Kemasan Boardgame Tangkas Berkata}

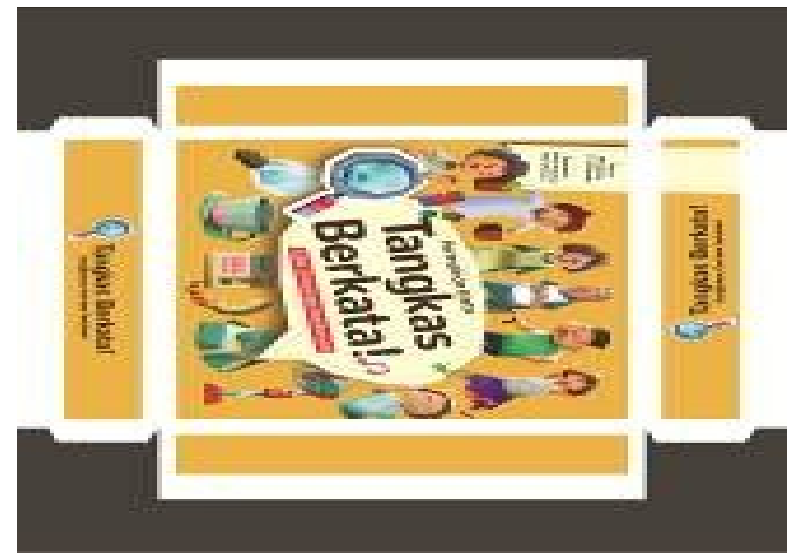

Gambar 10. Hasil akhir desain kemasan permainan sisi depan.

Desain akhir kemasan permainan mengakomodasi ukuran papan permainan dan menunjang ruang untuk penambahan kartu ekspansi untuk kedepannnya. Informasi permainan pada muka kemasan di sederhanakan agar, audiens dapat memproses informasi dengan mudah sekaligus dapat fokus pada judul permainan yang tertampil pada kemasan.

Tampilan pada sisi kemasan digunakan sebagai penanda agar produk dapat dikenali jika dilihat dari berbagai sisi. Warna supergrafis bewarna kuning untuk edisi kemasan keluarga dan Rumah. Warna yang berbeda akan digunakan untuk edisi-edisi selanjutnya.

Desain kemasan bagian bawah boardgame berfungsi sebagai informasi produk yang lebih detail. Untuk memberikan gambaran umum permainan kepada audiens. 


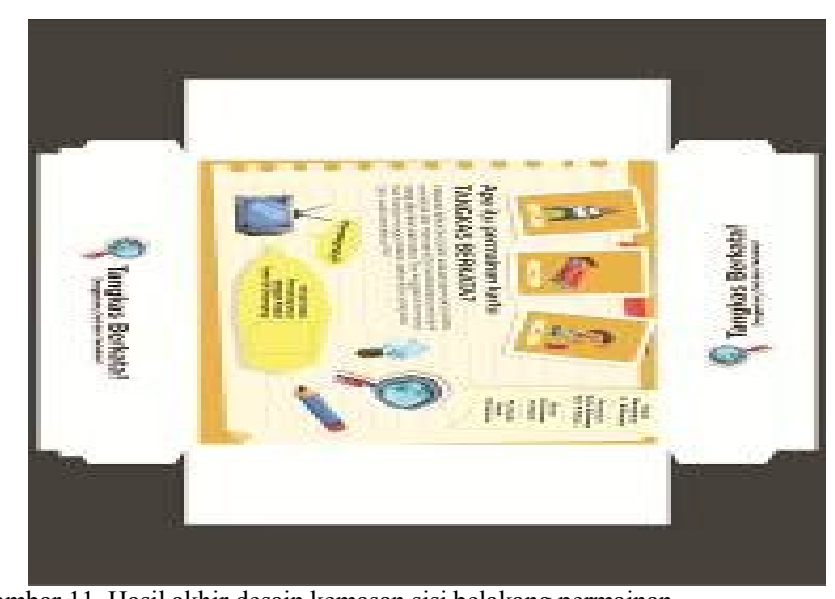

Gambar 11. Hasil akhir desain kemasan sisi belakang permainan.

\section{D.Implementasi}

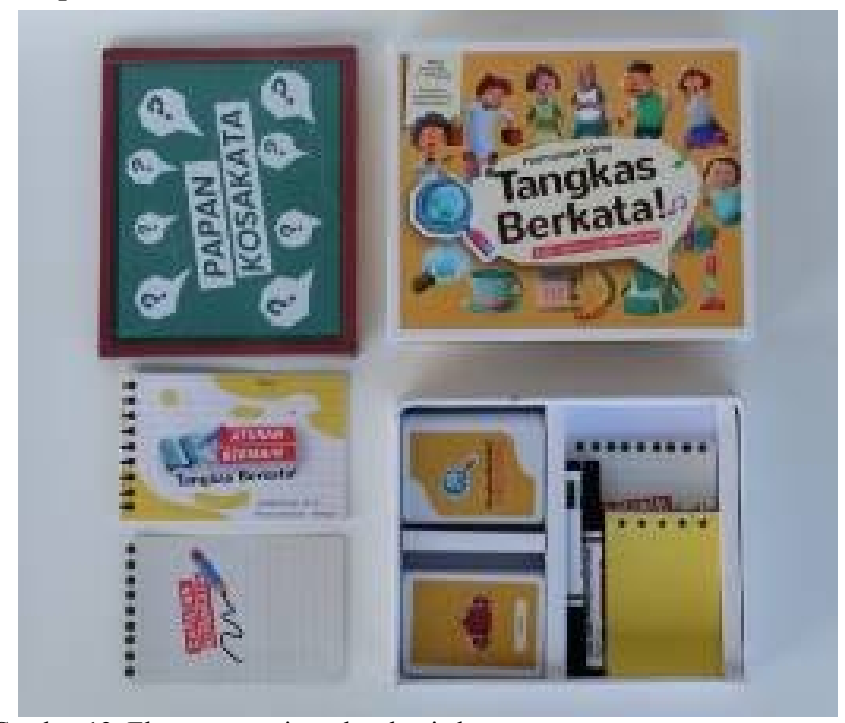

Gambar 12. Elemen permainan dan desain kemasan.

Produk di foto secara flatlay untuk melihat perbandingan ukuran elemen permainan satu dengan yang lain. Keseluruhan elemen permainan dikemas secara rapat dan pas.

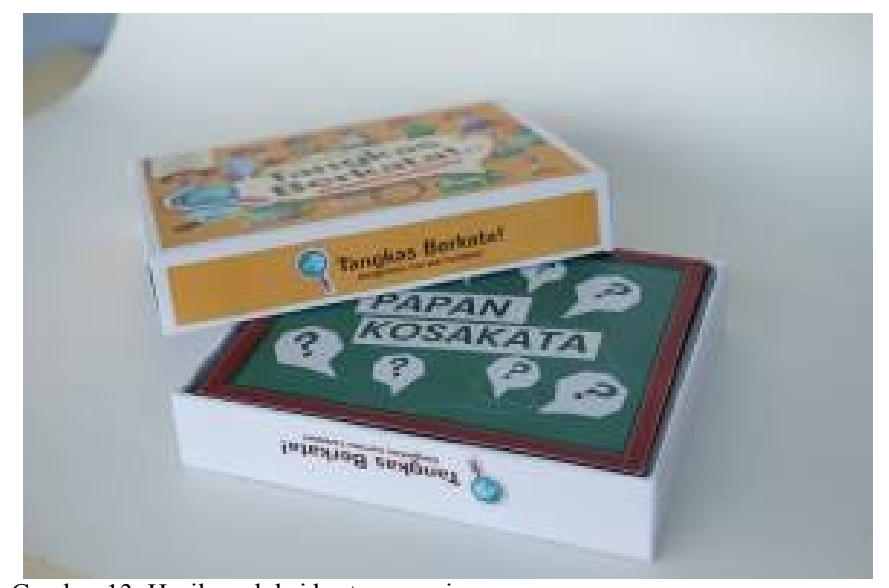

Gambar 13. Hasil produksi kartu permainan.

Papan permainan tampak berada dibagian atas sejajar dengan tinggi kemasaan, berguna untuk memudahkan pemain mengambil papan permainan didalam kemasan.

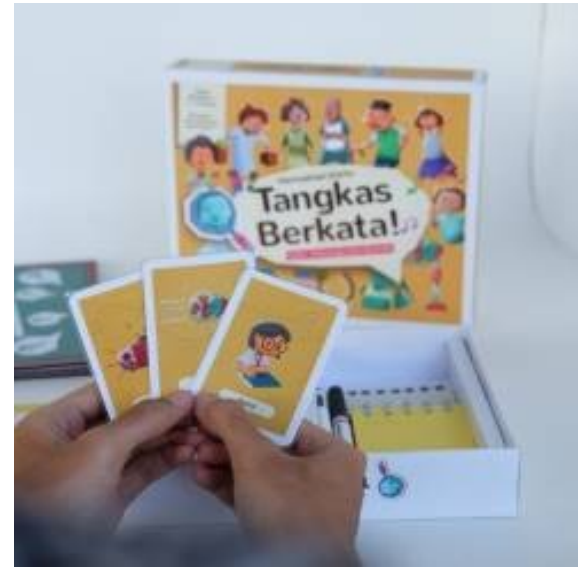

Gambar 14. Hasil produksi kartu permainan.

Kartu permainan terdapat setidaknya tiga jenis, yaitu kartu subyek dengan ilustrasi karakter, lalu kartu kata kerja yang menunjukan sebuah aktivitas karakter dan kartu kata benda, menggunakan ilustrasi benda seusai dengan teks.

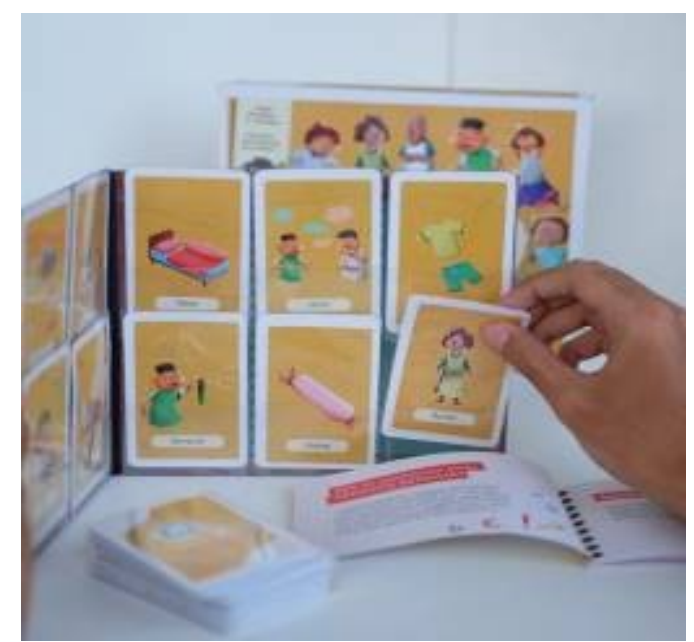

Gambar 15. Penggunaan papan permainan.

Papan permainan merupakan salah satu elemen permainan yang menunjang pengalaman dalam bermain, memiliki fungsi untuk memperlihatkan kartu kosakata yang dimainkan kepada pemain lain sekaligus menutup kartu secara bersamaan kepada pemain lain dan hanya diperlihatkan kepada satu pemain saja. Cara kerja papan permainan, dengan cara menyelipkan kartu pada sleve mika pada papan.

\section{KESIMPULAN}

Dalam proses penelitian peneliti menemukan bahwa Bahasa Indonesia terdapat banyak konten dan materi yang dapat diangkat, seperti Materi Struktur Kalimat, Puisi, Kosakata, Cerita, setelah beberapa prototype, konten Kosakata merupakan konten yang dapat diangkat kedalam mekanik permainan karena memiliki parameter benar dan salah yang jelas dan tidak ada potensi munculnya informasiinformasi non-edukatif, yang dapat mengganggu proses belajar kreatif pada anak maupun keluarga..

Tingkat kesulitan dalam Tangkas Berkata dapat diatur seusai dengan umur dan wawasan pemain dalam mengenal kosakata, dalam proses permainan terdapat transfer ilmu, 
kepada pemain lain karena para peman dituntut untuk dapat saling berkomunikasi dan menjelaskan kosakata yang ada. Dengan Downtime sebesar 30 detik dirasa cukup oleh seorang anak untuk menulis kosakata yang ada, dan 90 detik untuk menebak semua kosakata yang telah ditulis. Tantangan dapat ditambahkan kedalam permainan dengan mengurangi durasi downtime pada para pemain.

Papan permainan berhasil mengakomodasi pengalaman bermain, dimana para pemain dapat menutup secara singkat dan cepat keseluruhan kartu kosakata yang ada hanya dengan satu gerakan. Berbeda sebelumnya ketika elemen papan pemainan tidak ada. Untuk itu papan permainan menjadi elemen vital dalam proses bermain.

\section{DAFTAR PUSTAKA}

[1] A. Na'im, Kewarganegaraan, suku bangsa, dan bahasa sehari-hari penduduk indonesia. 2011.

[2] Badan Pengembangan Bahasa dan Perbukuan, "Rencana Strategi Badan Bahasa," Jakarta, 2015.

[3] B. Brathwaite and I. Schreiber, Challenge for game designer. Boston: Course Technology, 2009. 